be disappointed to find that the work reported is now two years old.

The book contains a series of 55 separate papers which are collected under ten different sub-titles. The first four titles deal with the regulation of growth and differentiation, the fifth concerns 'Biological Interactions in Carcinogenesis', the sixth group of papers deals with 'Interactions of Cells and Tissues in Organised Systems', and the seventh with 'Enzyme Patterns in Growth and Differentiation'. The eighth group covers the 'Systemic Aspects of Neoplastic Disease' while the last two subheadings deal with invasion and metastasis.

Full references are quoted at the end of each paper, while after each group of papers there is an account of the discussion which followed at the end of the session concerned.

This volume, which is well-printed and produced to the usual high American standard, should be of the greatest interest to readers who are concerned with the mechanisms by which cancer cells live within and invade the normal tissues of the host.

It will be a valuable reference book for the library, even though the reader who wishes to have up-to-theminute information will still need to attend meetings in person.

\section{Problems of Radiobiology, Vol. 2}

Transactions of the Central Roentgenological and Radiological Institute of the Ministry of Health of the U.S.S.R. Translated from the Russian Jerusalem: Israel Program for Scientific Translations. 1962. 70s.

The volume consists of a collection of 54 papers by different authors. The majority of the articles deal with the biological effects of radiation on animals, and individual tissues and systems of the body. The last three articles deal with the use of gamma ray beam units. In these three articles problems of dosimetry are discussed from the point of view of the mathematical physicist, and would be of less interest to the clinical therapist.

The first five papers in the volume deal with general problems connected with the effects of radiation, the next six describe the effects of radiation on the metabolism of nerve tissue and the effects on the functioning of various reflexes.

Other papers describe the results of combined radiation and traumatisation of tissues. The effects of radiation alone on various systems of the body are also described, including study of infectious complications and immunity in irradiated animals. Finally there is discussion of the problems of prophylaxis and treatment of radiation sickness. Different writers report advantage from the use of very varied substances, for example the administration of hyaluronic acid (obtained from the vitreous of eyes), ethylthiourea, vit. $\mathrm{B}_{12}$, and campolon combined with ATP were all found to be helpful.

This book almost entirely consists of reports of experimental findings and so contributes further to the already vast pool of information which the world possesses on these subjects.

These translations of Russian publications are to be welcomed since improved exchange of information and ideas can only be for the good, and helpful to understanding of common problems.

\section{Shaw's Textbook of Gynacology}

Revised by JoHN Howkins. Eighth edition. Pp. 852, with four colour plates and $45 \mathrm{I}$ text figures. London: J. \& A. Churchill. 1962. 40s.

Shaw's Textbook of Gynæcology was first published in 1936 and the eighth edition by Mr. Howkins appears six years after the last edition. Gynæcology is a subject that is advancing so rapidly that this new edition was perhaps overdue, but it lives fully up to the standards that one expects from this well established volume.

Mr. Howkins has re-written a considerable amount of the text and that which he has not actually re-written he has revised fully so as to align it with the modern trends of British gynæcology. This book is well known for its excellent illustrations and the 99 additional illustrations account for about half of the i 1 I additional pages. Venereal disease has now been allocated a chapter of its own under the authorship of Dr. Claude Nicol and Mr. I. G. Williams's chapter on radiotherapy deserves special mention, for its contents, simplicity and clarity of presentation. The illustrations throughout are of a high standard with the exception of Fig. $5 \mathrm{I}$, in which some of the lettering is upside down. The standard of reproduction of the photomicrographs is particularly high, and their inclusion together with a large amount of gynæcological pathology has always been a particular feature of Shaw's Gynæcology. The presentation of sex and intersexuality in one chapter is a decided advantage with the relationship between the various abnormalities being clearly defined and well illustrated. Increased stress has been laid upon the early diagnosis of carcinoma of the cervix, but treatment of trichomonas vaginitis could more conveniently be considered in this chapter rather than in that which deals with sexually transmitted diseases in the female.

Dr. Sylvia Dawkins's chapter on birth control is another model of clarity, but her instructions would be of even greater value if she gave an accurate description of how to fit the correct size of occlusive diaphragm. She skips rather lightly round the vexed question of oral contraception. Perhaps this volume appeared a little too soon for definite views to be established.

The chapters on endometriosis and ovarian tumours have been almost completely re-written. The glossary at the end of the book is a fascinating and informative addition.

This is an excellent book. It teaches not only the facts of gynæcology but also the histological, pathological and physiological fundamentals that form the basis of the modern practice of British gynæcology.. It should be read by every undergraduate and there are few postgraduate students who will not benefit from a detailed study of Mr. Howkins's new edition. This book also possesses and transmits the author's own enthusiasm. There are few who read it who will not be stimulated by its contents.

\section{Dental Anthropology}

Edited by D. R. Brothwell. Vol. 5 of Symposia of the Society for the Study of Human Biology. Pp. vii +288 illustrated. Oxford, London, New York and Paris: Pergamon Press. 1963. 70s.

This is the first symposium on dental anthropology and the fifth volume of symposia published by the Society of Human Biology whose aim is to advance the study of human populations and of man as a species especially of human variability, genetics and evolution.

This symposium goes far to fulfil this aim, although the present work is limited to the teeth, it covers a wide range within these limitations including developmental aspects, morphological variability in earlier and modern primates, genetic studies and pathological anomalies in earlier populations.

It is indeed surprising that whilst dental anthropology has hitherto been a productive field of research yet there are so very few comprehensive works such as this 